\title{
APPLICATION OF COMPLEX INSTRUMENTAL TECHNIQUES, SPECTROSCOPY AND CHROMATOGRAPHY, FOR THE ANALYSIS OF BIOFUELS AND BIOMASS
}

\author{
Tatjana Tomić*, Jelena Parlov Vuković* \\ * INA - Industrija nafte d.d., Product Development Department, Central Testing Laboratory, Zagreb, Croatia \\ corresponding author: Tatjan Tomić, e-mail: tatjana.tomic@ina.hr
}

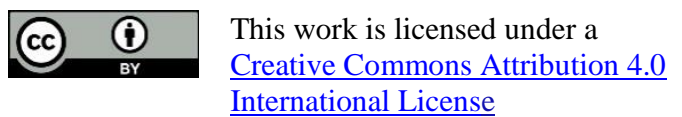

\author{
Preliminary note \\ Received: February $18^{\text {th }}, 2019$ \\ Accepted: April $26^{\text {th }}, 2019$ \\ HAE-1907 \\ https://doi.org/10.33765/thate.9.3.2
}

\begin{abstract}
Biofuels are environmentally friendly alternative fuels produced from animal and plant raw materials. They have great significance due to limited availability of crude oil and increased ecological requirements. The development of biofuels is followed by the development of new and more efficient analytical procedures for monitoring the composition and physical-chemical properties. This paper presents the application of chromatographic and spectroscopic methods in the analysis of different types of biofuels. The results of the determination of the hydrocarbon composition and functional groups important for the application of biofuels as blending components are shown. In this paper, it has confirmed the possibility of using NMR spectroscopy, HPLC and IC chromatography in biofuel and biomass analysis.
\end{abstract}

Keywords: biomass, biofuels, chromatography, spectroscopy

\section{INTRODUCTION}

Interest for the use of biomass and biofuels, such as bio-oils, oil bitumen and pyrolytic oils is growing rapidly in the area of environmental protection, economy and society in general [1]. The limited availability of crude oil reserves and the negative impact of the use of fossil fuels on the environment further encourage the use of alternative fuels [2]. After the introduction of biofuels of the first generation which are derived from edible raw materials, today the development turns to the biofuels of the second and the third generation which are derived from used raw materials and waste.
Efforts and resources to develop and produce energy from renewable sources are continuously invested.

Renewable energies such as solar energy, wind energy, hydro power plants, biomass and biofuels are effectively used for the transport of people and goods. The term biomass includes various animal and vegetable raw materials that can be used for energy production and composting [3]. Biomass is a renewable source of energy and represents an alternative to fossil energy sources. Depending on the type of used biomass, the first, the second and the third generation biofuels are 
distinguished. During last few years, animal fats and used vegetable oils are increasingly used as raw materials for biodiesel production. Furthermore, lipids isolated from algal biomass can also be used as a raw material for biodiesel production.

Most of the information about the chemistry of alternative fuel results from the data obtained from highly sophisticated spectroscopic and chromatographic methods. By combining chromatographic and spectroscopic techniques, detailed biofuels characterization can be obtained as well as the possibility of their further use as blending components. The paper presents the results of biofuel and biomass analysis by nuclear magnetic resonance (NMR) spectroscopy and liquid chromatography (HPLC, IC) and related conclusions regarding the hydrocarbon composition.

NMR spectroscopy is powerful and useful modern instrumental analytical technique which is increasingly used for characterization, structural and compositional analysis of biofuels and biomass [4 - 6]. It has many advantages over some routine chromatography and mass spectrometry methods such as simple sample preparation, faster analysis and use of small amount of solvents which is environmentally acceptable. HPLC is widely used in the analysis of crude oil, refined petroleum distillates and commercial petroleum products. Liquid chromatographic analysis of petroleum products includes separation and identification by group hydrocarbon types as well as separation, identification and quantification of target compounds. Various HPLC techniques involving the use of polar or nonpolar stationary phases, chromatographic columns and ion exchangers, different mobile phase compositions and detection systems enable the analysis of biofuels of different physicalchemical properties, solubility, density and polarity [7].

\section{EXPERIMENTAL}

\section{Ion chromatography system (IC)}

IC measurements were performed on Dionex ICS 3000 modular ion chromatography system (Dionex, USA) comprising high pressure pump, eluent generator module filled with $\mathrm{KOH}$ cartridge, IonPac AG 15 guard column and IonPac AS 15 analytical capillary column, suppressor and conductivity detector. Column dimension was $250 \mathrm{~mm} \times 4 \mathrm{~mm}$ and it was filled with polymeric material. Analysis run time was sat on 53 minutes, flow rate on 1.0 $\mathrm{mL} \mathrm{min}^{-1}$. Temperature of column department was set at $30{ }^{\circ} \mathrm{C}$ and of detector department was set at $20{ }^{\circ} \mathrm{C}$. For data processing Chromeleon software from Dionex was used.

In ion chromatography analyses the mobile phases was prepared by eluent generator cartridge filled with potassium hydroxide $(\mathrm{KOH})$ and with deionised water $(18 \mathrm{M} \Omega)$ obtained from TKA Pacific/Gen Pure water purification system (TKA Water Purification Systems GmbH, Germany). The mobile phase ion strength was set by the computer program and concentration of $\mathrm{KOH}$ was $25 \mathrm{mM}$. For calibration, stock standard solution (Dionex, USA) was diluted to appropriate concentrations, and calibration graph was constructed with five calibration points in concentration range from $0.1 \mathrm{mg} \mathrm{L}^{-1}$ to $20 \mathrm{mg}$ $\mathrm{L}^{-1}$. All samples were filtered through a 0.45 $\mu \mathrm{m}$ regenerated cellulose membrane filter and injection volume was set on $10 \mu \mathrm{L}$.

\section{High performance liquid chromatography system (HPLC)}

Liquid chromatography system used for analyses is a complex modular system consisting of the following units: 9012Q HPLC pump (Varian Chromatography System, California, USA), injection system (ProStar 410 Autosampler, Varian), column oven (Mistral Column Oven, Varian), refraction index detector (Varian 9040), and STAR software program (Varian) for data processing. Aromatic hydrocarbons are separated from 
saturates and form distinct peaks according to their ring structure as mono-aromates (MA), di-aromates (DA), and tri-aromates (TA) on the Zorbax polar amino-bonded silica column dimensions $250 \mathrm{~mm} \times 4 \mathrm{~mm}$; particle size 5 um (Agilent, CA, USA). n-Heptane was used as mobile phase with $0.8 \mathrm{~mL} \mathrm{~min}^{-1}$ flow rate. The column temperature was set at $30{ }^{\circ} \mathrm{C}$, and injection volume was $10 \mu \mathrm{L}$. Samples were analysed on RI-detector capable of being operated over the refractive index range $1.3-$ 1.6. Analysis time was 30 minutes. Determination of concentrations of each aromatic species is based on calibration curves prepared using cyclohexane, o-xylene, 1methylnaphtalene, and phenanthrene. Calibration is performed with four calibration standards in concentration range from 0.05 to $4.0 \mathrm{~g} \mathrm{~mL}^{-1}$ for MA, from 0.02 to $2.0 \mathrm{~g} \mathrm{~mL}^{-1}$ for $\mathrm{DA}$, and from 0.01 to $0.4 \mathrm{~g} \mathrm{~mL}^{-1}$ for TA. Coefficients of correlation were higher than 0.99. Samples were dried over sodiumsulphate anh., diluted by n-heptane and before injection filtered through $0.5 \mu \mathrm{m}$ membrane filters. $10 \mu \mathrm{l}$ of prepared solution was injected.

\section{Liquid state NMR spectroscopy}

All the NMR spectra were recorded on a Bruker Avance 300 NMR spectrometer operating at $300 \mathrm{MHz}$ for ${ }^{1} \mathrm{H}$ and $75 \mathrm{MHz}$ for ${ }^{13} \mathrm{C}$ using a $\mathrm{C} / \mathrm{H}$ dual $5 \mathrm{~mm}$ probe. The spectra were recorded in DMSO-d6 and $\mathrm{CDCl}_{3}$ with a sample concentration of $20 \mathrm{mg} \mathrm{mL}^{-1}$ and TMS as the internal standard. Proton spectra with spectral width of $6200 \mathrm{~Hz}$ and a digital resolution of $0.09 \mathrm{~Hz}$ per point were measured with 64 scans. DOSY experiments were carried out using DgcsteSL_cc (DOSY gradient compensated stimulated echo with spin lock and convection compensation) pulse sequence with gradient strengths from 2.4 to $57.1 \mathrm{G} \mathrm{cm}^{-1}$, diffusion gradient length of 3.0 $\mathrm{ms}$ and diffusion delay of $50.0 \mathrm{~ms}$. Spectra were obtained with a $14368 \mathrm{~Hz}$ sweep width, $0.682 \mathrm{~s}$ acquisition time, $7.0 \mu \mathrm{s}\left(90^{\circ}\right)$ pulse width, $4 \mathrm{~s}$ delay time and 16 scans at temperature of $298 \mathrm{~K}$. Chemical shifts were referenced to the signal of TMS.

\section{Solid state NMR spectroscopy}

Solid state NMR spectra were recorded on Bruker Avance 300 spectrometer equipped with a $4 \mathrm{~mm}$ broad band magic angle spinning (MAS) probe. The samples for ${ }^{13} \mathrm{C}$ CP-MAS spectra were spun at the magic angle with 10 $\mathrm{kHz}$. External references were adamantane and glycine. The spectra were acquired with 8000 scans and repetition delay of 7 seconds.

\section{RESULTS AND DISCUSSION}

\section{NMR spectroscopy}

In recent years, new different methods for the analysis of biofuels and biomass by nuclear magnetic resonance have been developed. NMR can be applied to analyse biodiesel, diesel and biodiesel mixtures and it can provide detailed molecular information [8].

By definition, biodiesel is a mixture of monoalkyl esters of long chain fatty acids derived from different types of oils or animal fats. Commercially, biodiesel is produced by chemical transesterification of oil with alcohol in the presence of a catalyst. For biodiesel production various feedstock can be used and based on type of feedstock biodiesel can be categorised as first-, second- and thirdgeneration. First generation biodiesel is produced from edible oils and fats, second generation is produced from nonedible crops and wastes, while third generation is produced from microalgae [9]. The combustion of biodiesel greatly reduced emissions. ${ }^{1} \mathrm{H}$ NMR spectroscopy has been frequently used for the quantitative and qualitative analysis of vegetable oils, animal fats and their derivatives $[6,10]$. A typical ${ }^{1} \mathrm{H}$ NMR spectrum of fatty acid methyl esters (FAME) is displayed in Figure 1.

This spectrum shows all the characteristic signals of fatty acids, such as that observed between 0.8 and 1.7 and $2.27 \mathrm{ppm}$. Also, signals of unsaturated fatty acids are detected 
at 2.01 and $5.35 \mathrm{ppm}$ and polyunsaturated acids at $2.77 \mathrm{ppm}$.

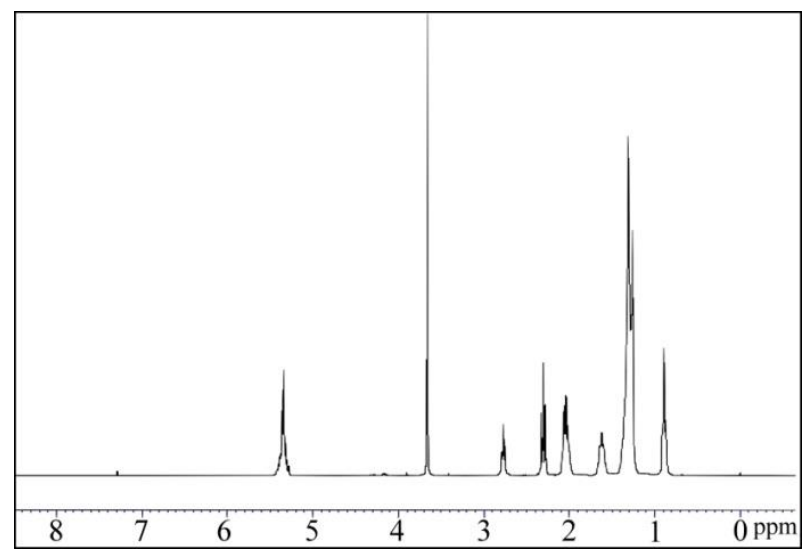

Figure 1. Typical ${ }^{1} \mathrm{H}$ NMR spectrum of fatty acid methyl esters

The group of authors investigated the fatty acid profile by ${ }^{1} \mathrm{H}$ NMR spectroscopy and developed a method for quantification of fatty acids in the mixture [11]. The method was applied to mixtures containing the triacylglycerol or alkyl esters of palmitic, stearic, oleic and linoleic acids. Theoretically, this method could be applied to oils or fats containing other fatty acids. Most physical properties of biodiesel are very similar to fossil diesel and it can be used pure or mixed with fossil diesel. NMR spectroscopy in combination with principal component analysis (PCA) has been shown to be a powerful tool for determining biodiesel present in blends and in identifying the biodiesel sources [2]. M. Oromi-Farrus et all analysed iodine values of biodiesel samples with 1,4-dioxane as an internal standard comparing result of ${ }^{1} \mathrm{H}$ NMR spectroscopy and standard iodometric method. The obtained results have showed good correlation. The iodine value parameter represents the total degree of unsaturation in vegetable oils and fats. Determination of the content of iodine value is very important. High iodine value can cause serious problems such as formation of various degradation products that is related to engine problems. The biodiesel has some disadvantages over fossil diesel such as oxidative stability. There are many factors which influence the oxidative stability of biodiesel and it has been reported that the oxidative stability is one of the most critical issue in production and use of biodiesel because it affects the quality of the fuel [12]. Also, the quality of biodiesel largely depends on quality of feedstock. G. Knothe explored the possibilities of NMR techniques to analyse oxidized biodiesel and the effect of contact area with air. The results showed that increasing surface area accelerated oxidation and affected fatty acid composition.

${ }^{13} \mathrm{C}$ NMR spectroscopy was used to determine fatty acid distribution in triacylglicerols of vegetable oils with high-low oleic and high linolenic acid [13]. Also, 1D and 2D NMR spectroscopy has been applied to monitor the transesterification reaction [14]. ${ }^{1} \mathrm{H} \quad \mathrm{NMR}$ DOSY technique was applied to examine acylglycerols and fatty acid methyl ester [15]. DOSY technique relies on molecular translational diffusion. It can be used to identify different compounds present in the complex sample according to their differences in diffusion properties. Furthermore, DOSY can provide information about the size and shape of each compound present in the mixture. Group of authors have been reported that NMR spectroscopy can be used for estimation of free fatty acid content in oils, fats and biodiesel [15]. The observed result was more accurate than the conventional titrimetric analysis for the estimation of FFA content. The necessity to reduce greenhouse gas emissions has increased interest in biomass lignocellulose. Liquid and solid state CP/MAS ${ }^{13} \mathrm{C}$ NMR spectroscopy has been proven powerful tool for characterization of biomass, lignin and cellulose. It has been reported that NMR spectroscopy is a promising technique for the analysis of biomass polymers [16, 17]. During investigation a typical ${ }^{13} \mathrm{C} \mathrm{CP} / \mathrm{MAS}$ NMR spectrum of cellulose is recorded (Figure 2). Cellulose is isolated from biomass Miscanthus X Giganteus. All characteristic signals of cellulose are observed between 66 and $110 \mathrm{ppm}$. Typical ${ }^{1} \mathrm{H}$ NMR 2D DOSY spectrum of cellulose is displayed in the Figure 3. 


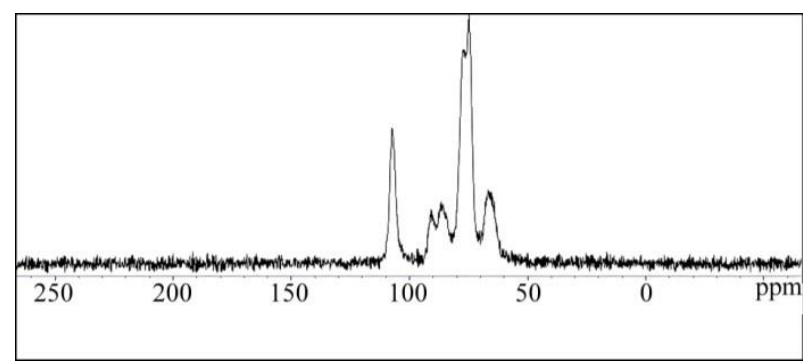

Figure 2. Typical ${ }^{13} \mathrm{C} \mathrm{CP/MAS} \mathrm{NMR} \mathrm{spectrum}$ of cellulose

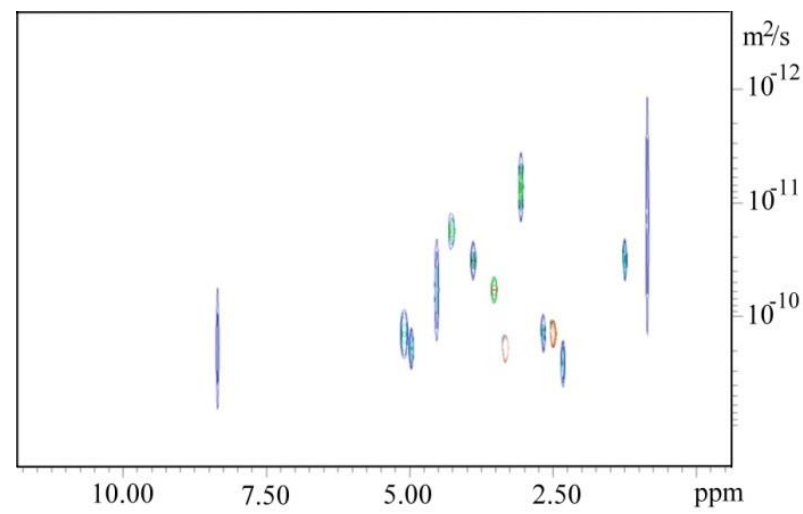

Figure 3. Typical ${ }^{1} \mathrm{H}$ NMR 2D DOSY spectrum of cellulose

\section{High Performance Liquid Chromatography (HPLC)}

The mixtures of pyrolytic oil obtained from different sources and diesel fuel were investigated by liquid chromatography in terms of determining the aromatic hydrocarbon composition. Normal phase high performance liquid chromatography (NPHPLC) which is generally used in the analysis of organic samples was used in aromatic hydrocarbon content determination in diesel fuels in which biocomponents were added. Addition of biocomponents of different origin to diesel fuel significantly decreases the content of aromatic hydrocarbons in fuel. It is especially important to monitor the polyaromatic hydrocarbons (PAH) content which is by regulation limited to maximum of $8 \%$ $(\mathrm{m} / \mathrm{m})$. The hydrocarbon composition of the mixtures formed by the mixing of pyrolytic oil and diesel fuel was monitored. (Figure 4).

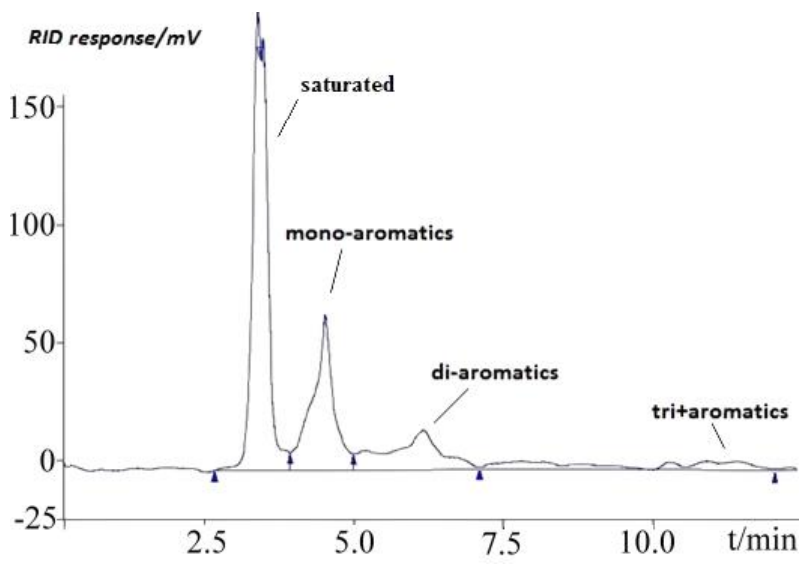

Figure 4. HPLC chromatogram of pyrolytic oil and diesel fuel mixture

\section{Ion Chromatography (IC)}

The analysis of bio-ethanol used as bio-fuel component in terms of the chloride and sulphate content determination by ion chromatography was performed. The content of chloride and sulphate in ethanol is monitored due to their impact on corrosion and precipitation formation. Ion chromatography method is suitable for simultaneous determination of chloride and sulphate ions in bio-ethanol at low concentration levels with good accuracy and avoiding laborious sample preparation [18]. The analysis requires a small amount of the test sample, and the duration of the analysis is relatively short. In four real bioethanol samples used as the components for the fuel blending, the content of the present chloride and sulphate ions was determined. Chromatogram of bio-ethanol sample as representative chromatogram is presented in Figure 5.

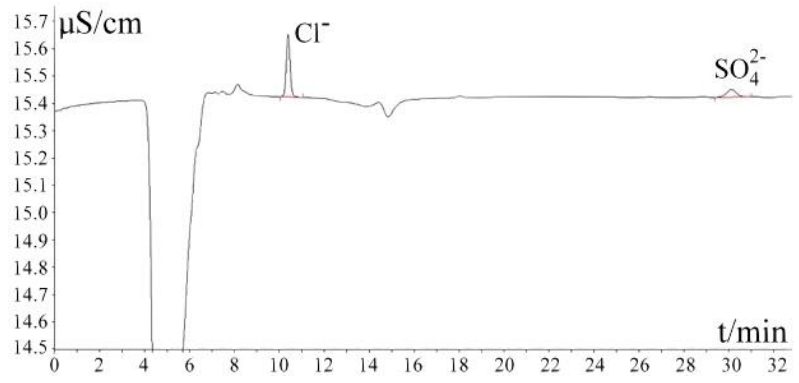

Figure 5. Chromatogram of a real bio-ethanol sample [18] 
Total time of analysis was 35 minutes and when analysing a real sample, the sulphate retention time is slightly longer compared to the standard. The content of chloride and sulphate ions in analysed samples obtained in units of $\mathrm{mg} \cdot \mathrm{L}^{-1}$ was expressed in $\mathrm{mg} \cdot \mathrm{kg}^{-1}$ taking into account density of each bio-ethanol sample. Quantitative results of the chloride and sulphate content determination in the bioethanol samples are shown in Table 1.

Table 1. Chloride and sulphate concentrations, $w\left(\mathrm{mg} \cdot \mathrm{kg}^{-1}\right)$ [18]

\begin{tabular}{|c|c|c|}
\hline $\begin{array}{c}\text { Bio-EtOH } \\
\text { sample no. }\end{array}$ & $\begin{array}{c}\text { chloride } \\
w\left(\mathrm{mg} \cdot \mathrm{kg}^{-1}\right)\end{array}$ & $\begin{array}{c}\text { sulphate } \\
w\left(\mathrm{mg} \cdot \mathrm{kg}^{-1}\right)\end{array}$ \\
\hline 1 & 0.36 & 0.22 \\
\hline 2 & 0.29 & 1.26 \\
\hline 3 & 0.29 & 0.82 \\
\hline 4 & 0.44 & 0.21 \\
\hline
\end{tabular}

IC was used to determine the water-soluble content of chloride, sodium and potassium in solid biofuels (Figures 6 and 7), such as Miscanthus $\mathrm{X}$ Giganteus. Combustion of biomass leads to the formation of ash deposits which can have some content of chloride, sodium and potassium. The content of chloride, water-soluble sodium and potassium is monitored due to formation of deposits and corrosion. The preparation of biomass samples for ion chromatography analysis involves hydrolytic thermal decomposition and filtration. Quantitative results of the chloride sodium and potassium content determination in the Mischantus are shown in Table 2.

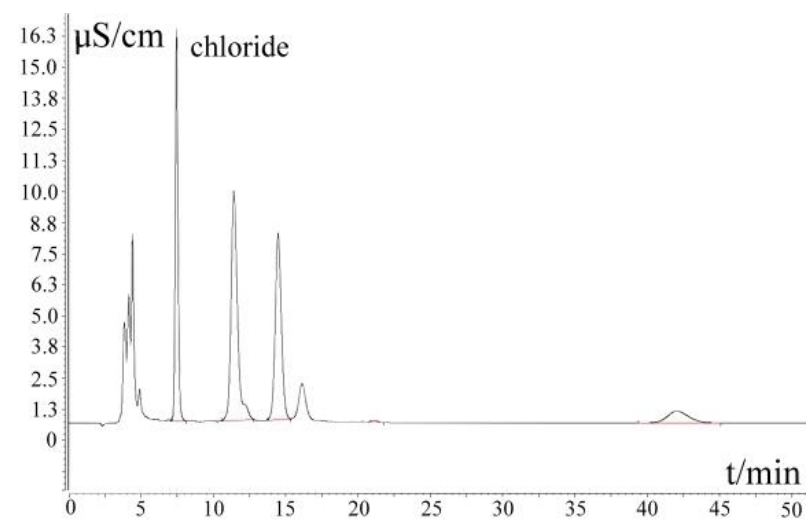

Figure 6. Ion chromatographic analysis of Miscanthus aqueous solution, anion separation

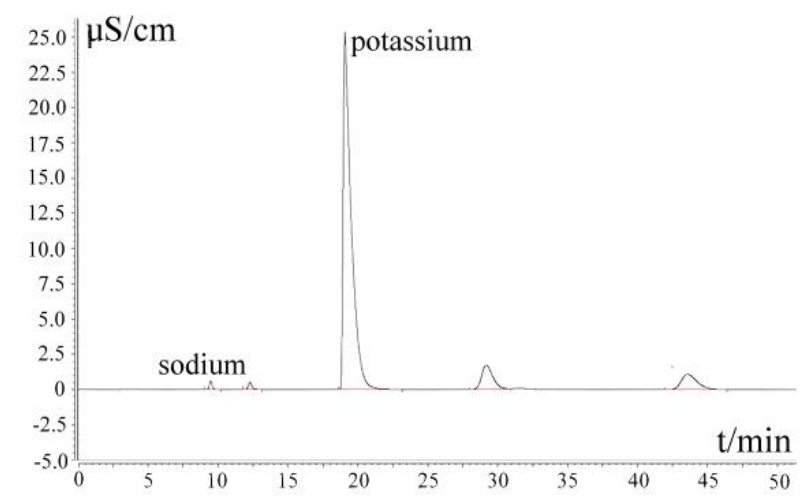

Figure 7. Ion chromatographic analysis of Miscanthus aqueous solution, cation separation

Table 2. Chloride, sodium and potassium concentrations, $w\left(\mathrm{mg} \cdot \mathrm{kg}^{-1}\right)$

\begin{tabular}{|c|c|c|c|}
\hline $\begin{array}{c}\text { solid } \\
\text { biofuel } \\
\text { sample }\end{array}$ & $\begin{array}{c}\text { chloride } \\
w \\
\left(\mathrm{mg} \cdot \mathrm{kg}^{-1}\right)\end{array}$ & $\begin{array}{c}\text { sodium } \\
\left(\mathrm{mg} \cdot \mathrm{kg}^{-1}\right)\end{array}$ & $\begin{array}{c}\text { potassium } \\
\left(\mathrm{mg} \cdot \mathrm{kg}^{-1}\right)\end{array}$ \\
\hline Miscanthus & 485 & 86 & 1860 \\
\hline
\end{tabular}

\section{CONCLUSION}

In this paper we have shown the results of scientific efforts to follow the development of new, more environmentally friendly fuels with advanced analytical techniques. By HPLC technique, the content of aromatic hydrocarbons in the fuel in which the byocompound was mixed could be monitored as aromatic hydrocarbons are strong ecological pollutants and carcinogenic substances. By IC the content of chloride and sulphate in bioethanol used for blending into gasoline was monitored, as well as the content of chloride and water-soluble sodium and potassium in biomass. It has been shown that NMR spectroscopy is very promising technique for structural and compositional analysis of biomass and biofuels. It has been demonstrated that the development of new ecological fuels is only possible with the development of advanced analytical techniques. 


\section{REFERENCES}

[1] I.S. Flores, M.S. Godinho, A.E. Oliveria, G.B. Alcantara, M.R. Monteiro, S.M.C. Menezes, L.M. Liao, Discrimination of biodiesel blends with ${ }^{1} \mathrm{H} \quad \mathrm{NMR}$ spectroscopy and principal component analyses, Fuel 99(2012), 40-45.

[2] E. Stauffer, D. Byron, Alternative Fuels in Fire Debris Analysis: Biodiesel Basics, Journal of Forensic Sciences 52(2007) 2, 371-379.

[3] M. Antonelli, A. Baccioli, M. Francesconi, P. Psaroudakis, L. Martorano, Technologies for Energy Recovery from Waste Biomasses: A Study about Tuscan Potentialities, Energy Procedia 81(2015), 450-460.

[4] J. Parlov Vuković, Primjena spektroskopije NMR u analizi biodizela, Kemija u industriji 65(2016) 1-2, 17-24.

[5] M. Foston, Advances in solid-state NMR of cellulose, Current Opinion in Byotechnology 27(2014), 176-184.

[6] D. Castejón, I. Mateos-Aparicio, M.D. Molero, M.I. Cambero, A. Herrera, Evaluation and Optimization of the Analysis of Fatty Acid Types in Edible Oils by ${ }^{1} \mathrm{H}-\mathrm{NMR}$, Food Analytical Methods 7(2014) 6, 1285-1297.

[7] M. Mittelbach, Diesel fuel derived from vegetable oils, VI: Specifications and quality control of biodiesel, Bioresource Technology 56(1996), 7-11.

[8] J. Parlov Vuković , V. Srića, P. Novak, Primjena spektroskopije NMR u analizi naftnih derivata i proizvoda, Kemija u industriji 61(2012) 11-12, 513-522.

[9] A. Sander, M.A. Košćak, D. Kosir, N. Milosavljević, J. Parlov Vuković, L. Magić, The influence of animal fat type and purification conditions on biodiesel quality, Renewable Energy 118(2018), 752-760.

[10] R.I. Almoselhy, M.H. Allam, M.H, ElKalyoubi, A.A. El-Sharkawy, ${ }^{1} \mathrm{H}$ NMR spectral analysis as a new aspect to evaluate the stability of some edible oils, Annals of Agricultural Sciences 59(2014), 201-206.
[11] G. Knothe, A. Kenar, Determination of the fatty acid profile by ${ }^{1} \mathrm{H}-\mathrm{NMR}$ spectroscopy, European Journal of Lipid Science and Technology 106(2004), 8896.

[12] G. Vlahov, ${ }^{13} \mathrm{C}$ Nuclear Magnetic Resonance Spectroscopy to Determine Fatty Acid Distribution in Triacylglycerols of Vegetable Oils with High - Low Oleic Acid and High Linolenic Acid, The Open Magnetic Resonance Journal, 2(2009), 8-19.

[13] M. Horst, S. Urbin, R. Burton, C. MacMillan, Using proton nuclear magnetic resonance as a rapid response research tool for methyl ester characterization in biodiesel, Lipid Technology 21(2009), 1-3.

[14] A.M. Socha, G. Kagan, W. Li, R. Hopson, J.K. Sello, P.G. Williard, Diffusion Coefficient-Formula Weight Correlation Analysis via DiffusionOrdered Nuclear Magnetic Resonance Spectroscopy (DOSY NMR) To Examine Acylglycerol Mixtures and Biodiesel Production, Energy\&Fuels 24(2010) 8, 4518-4521.

[15] K. Jitendra, D. Srinivas, P. Ratnasamy, Estimation of Free Fatty Acid Content in Oils, Fats, and Biodiesel by ${ }^{1} \mathrm{H}$ NMR Spectroscopy, Energy \& Fuels 23(2009), 2273-2277.

[16] H. Kono, S. Yunoki, T. Shikano, M. Fujiwara, T. Erata, M. Takai, CP/MAS ${ }^{13} \mathrm{C}$ NMR Study of Cellulose and Cellulose Derivatives. 1. Complete Assignment of the CP/MAS ${ }^{13} \mathrm{C}$ NMR Spectrum of the Native Cellulose, Journal of the American Chemical Society 124(2002) 25, 7506-7511.

[17] K. Kamide, K. Okajima, K. Kowsaka, T. Matsui, CP/MAS ${ }^{13} \mathrm{C}$ NMR spectra of cellulose solids: an explanation by the intramolecular hydrogen bond concept, Polymer Journal 17(1985), 701-706.

[18] T. Tomić, M. Milčić, N. Uzorinac Nasipak, S. Babić, Characterization of ions in bio-ethanol used for bio-fuel blending, The Holistic Approach to Environment 7(2017) 4, 169-176. 